\begin{tabular}{|c|c|}
\hline Postprint Version & 1.0 \\
\hline Journal website & http://www.sciencedirect.com/science/journal/01688510 \\
\hline Pubmed link & $\begin{array}{l}\text { http://www.ncbi.nlm.nih.gov/entrez/query.fcgi?db=pubmed\&cmd=Retrieve\&dop } \\
\mathrm{t}=\text { AbstractPlus\&list_uids=16787681\&query_hl=1\&itool=pubmed_docsum }\end{array}$ \\
\hline DOI & 10.1016/j.healthpol.2006.05.008 \\
\hline
\end{tabular}

\title{
Physical therapy management of low back pain has changed
}

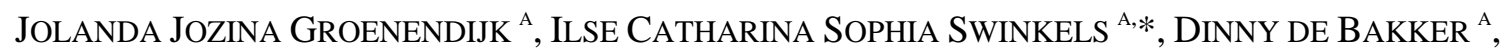 \\ JOOST DEKKER ${ }^{\mathrm{B}}$, CORNELIA HELENA MARIA VAN DEN ENDE ${ }^{\text {A }}$ \\ ${ }^{a}$ NIVEL, Netherlands Institute for Health Services Research, P.O. Box 1568, 3500 BN Utrecht, The \\ Netherlands \\ ${ }^{\mathrm{b}}$ Department of Rehabilitation Medicine, Institute for Research in Extramural Medicine, VU University \\ Medical Centre Amsterdam, P.O. Box 7057, 1007 MB Amsterdam, The Netherlands \\ * Corresponding author. E-mail address: i.swinkels@nivel.nl (I.C.S. Swinkels).
}

\begin{abstract}
Background: Since the 1990s, new insights in the physical therapy management of low back pain have been described in guidelines. Furthermore, insurance companies introduced a volume policy to control the costs for physical therapy.

Objective: This study aims to establish if developments in knowledge and health policy since the 1990s have resulted in changes in the physical therapy management of patients with low back pain (LBP) in the Netherlands.

Methods: Data from 3148 patients, referred because of LBP, were selected from the databases of two registration studies (1989-1992 and 2002-2003) of patients treated by physical therapists. Descriptive statistics were used to compare patient characteristics. A multi-level regression analysis was carried out to determine a change in the number of treatment sessions adjusting for patient and disease characteristics, and to control for different levels (patient and physical therapist).

Results: A small decline in the number of treatment sessions was observed. In 2002, exercise therapy was the most frequently applied intervention, while massage and physical modalities were the interventions of first choice in the early 1990s.

Conclusion: Our results suggest that since 1990 the management of patients with LBP by physical therapists in the Netherlands has changed. Both quality management by the profession and volume policy by government and insurance companies seem to have been instrumental in bringing about a decline in the number of treatment visits and an increase in the use of evidence-based interventions.
\end{abstract}

Since the 1990s there have been several developments as well as new regulations within the Dutch physical therapy practice. In this study we want to establish if these changes have had an effect on the management of patients in the physical therapists' practice. We will focus on one complaint-specific group of patients, those with non-specific low back pain (LBP) because they form the largest population in physical therapy practice [1]. We hypothesize that due to quality policy by the profession and volume policy by government the number of visits per treatment episode has decreased and that a shift can be observed in the choice of interventions to a more active approach.

In 1990, a new quality policy in The Netherlands was deemed necessary because of the government's plan to introduce self-regulation and competitive elements in the health care system. To protect 
patients in a system with less government regulation, the quality of care had to be ensured. At national level, agreements about a new quality policy were made among all parties involved: the providers, patient organizations, insurers and the government [2,3]. In order to fulfil the quality requirements, the Royal Dutch Society of Physical Therapy adopted a program for continuous quality improvement in 1995. This program included four elements: continuing education, development and implementation of clinical practice guidelines, consultation platforms for quality improvement, and quality registration. The consultation platforms, consisting of 10-15 physical therapists working on quality improvement and assurance, are considered the heart of the quality assurance program and were established to encourage cooperation and communication among physical therapists and to aid implementation of the different elements of the quality program [4].

In 2001, the physical therapy guideline for the assessment and treatment of patients with non-specific low back pain was published [5]. The guideline recommends an active approach consisting of interventions such as 'instruction and advice' and 'exercise therapy' aiming at improvement of activities and participation [5]. The guideline states that one or two visits should be sufficient for patients with acute LBP with a normal course in whom activities gradually increase. Furthermore, the use of passive interventions such as massage, traction, ultrasound, electro therapy, and laser is not advised. This follows the recommendation of the Health Council of the Netherlands made in 1999 about the use of physical therapy modalities. In this report the use of physical therapy modalities is advised against because of the lack of evidence of its effectiveness [6]. The recommendations in the guideline for physical therapy followed the general practitioners' guideline about patients with LBP developed in 1996 by the Dutch College of General Practitioners. In this guideline the main recommendations were the activation of patients and the discouragement of bed rest. Furthermore, according to this guideline it is recommended not to refer patients with acute LBP to the physical therapist. Instead, patients should be advised to stay active and be given a prescription for medication, if necessary. For patients with chronic LBP exercise therapy might be beneficial; therefore, referral to an exercise therapist or physical therapist might be useful [7].

Next to these developments in the practice of physical therapy, there have also been changes in the governmental policy concerning physical therapy. Because of the increasing costs of health care the Minister of Health, Welfare and Sports passed a new regulation in 1996 which restricted the claim that people with public insurance, $66 \%$ of the Dutch population, could make on physical therapy to nine treatment visits [8]. Furthermore, from the beginning of 2000, in order to get more control over the quality and costs of physical therapy, public insurance companies started a 'volume policy'.

Benchmarking, i.e., comparing the volume of a particular practice with the average volume of the nation or region, is one of the instruments used for this policy. In some cases financial incentives are applied to encourage a lower average of treatment visits per physical therapist [2].

In this study we will test the following three hypotheses: first, it is expected, that the proportion of patients with acute LBP has declined between 1989 and 2002 because of the negative recommendation about referral of patients with acute LBP by the Dutch college of General Practitioners in 1996. Secondly, because of the changes in the reimbursement policy we expect to see a decrease in the number of visits within a treatment episode for patients with LBP. As the reimbursement policy is aimed at patients with public health insurance, we expect to see less decrease in patients with private health insurance than in patients with public health insurance. Finally, the expectation is that there will be a decline since 1989 in the use of physical therapy modalities and massage therapy and a rise in the use of 'instruction and advice' and 'exercise therapy' caused by the introduction of the guideline for the treatment of LBP by physical therapists in 2001 and the advice against physical therapy modalities by the Health Council of the Netherlands in 1999.

\section{METHODS}

\subsection{Design}

For this study we used data from two registration projects carried out in The Netherlands in 19891992 and 2002-2003. The aim of the first project was to gain insight into the physical therapy practice in the Netherlands. Eighty-three randomly selected physical therapists working in 32 physical therapy practices all over the country were included in this project. They supplied paper data on more than 16,000 patients [9]. The second source of data came from the National Information Service for Allied 
Health Care, a continuous computerized registration network existing of over 100 randomly selected Dutch physical therapists working in 40 physical therapy practices all over the country, which started in April 2001 [1]. From this database, data of patients with a referral date from July 2002 until May 2003 were selected. In both projects the participating physical therapists were representative for the Dutch population of physical therapists in primary care at that time with respect to the following factors: age, gender, number of working hours and years of experience.

Collected data in both projects included patient characteristics, the referring physician, the reason for referral, the duration of the complaint at the start of the treatment episode, the number of visits per treatment episode and the interventions used. All variables but the referral diagnosis were gathered by closed format questions (Table 1). In both projects the referral diagnosis was registered by the participating physical therapists in free text format. This free text was coded according to the International Classification of Primary Care by researchers [10]. Most of the variables in the two registration projects were collected in a similar way making comparison possible. The registration method of data about the kind of intervention differed, however. In the project carried out between 1989 and 1992, the physical therapist had to register in each visit which interventions with a maximum of four were used. In the project carried out between 2002 and 2003, the physical therapists where asked to register at the end of the treatment the three most important interventions that were used in more than $50 \%$ of all visits. Nevertheless, in both registrations the same classification of interventions was used, including the interventions 'physical therapy modalities', 'massage therapy', 'instruction and advice' and 'exercise therapy'. From the data in the first project, it was calculated which interventions were applied in at least $50 \%$ of the treatment visits. From these interventions, the three most applied interventions were used for comparisons with the second study.

\section{[ TABLE 1 ]}

\subsection{Patients}

Data of patients referred with the diagnosis: 'low back pain without radiation (ICPC-code L03)' and aged 18 years or older were selected from the two databases $(n=3148)$. A total of 1948 patients were selected from the project carried out between 1989 and 1992 and 1200 patients from the project between 2002 and 2003.When answering the research questions a distinction will be made between patients with chronic LBP (complaints over 3 months), sub-acute (complaints between 1 and 3 months) and acute LBP (complaints lasting 1 month or less).

\subsection{Data analysis}

For all variables but 'education' the percentage missing values was less than $1 \%$. For the variable 'education', 25\% of the data collected in 2000-2003 had missing values. Software program SPSS 11.5 was used for the bivariate analyses. Differences in categorical data between patients with LBP in 1989-1992 and 2002-2003 were tested using chi-square tests (significance level of 0.05). Independent samples $T$-tests (significance level of 0.05 ) were used to test differences in continuous data (age, number of treatment visits). The Mann-Whitney test was used to test the difference between education levels.

A multi-level regression analysis, using Software program MLwiN, was carried out to determine a change in the number of treatment visits per episode. We adjusted for gender, age, education, health insurance, type of referring physician, duration of complaint, physical therapist, and practice on the basis of former studies in which the influence of the above factors on the number of treatment visits was found [11,12]. Apart from analyses with all data, analyses were done separately for patients with public health insurance and patients with private health insurance, in order to investigate whether the effect differed between both groups of patients. Dummy variables were constructed to replace categorical variables. Because of the large amount of missing data for the variable 'education' we added a category 'unknown'. A multi-level analysis was used because the data had an intrinsically hierarchical nature: the patients (level 1) were nested in the sample of physical therapists (level 2) who were nested in a sample of practices (level 3). Therefore, the data were not independent violating a major assumption of traditional regression analysis. 


\section{RESULTS}

\subsection{Patient characteristics}

The proportion of patients with LBP in the population of patients visiting the physical therapist has grown significantly between 1989 and 2002 (Table 2). Particularly, the proportion of women with LBP has increased by 3\%. Furthermore, the proportion of patients with acute LBP has not changed while the proportion of patients with sub-acute and chronic LBP has grown significantly since 1989.

\section{[ TABLE 2 ]}

In Table 3 there is a general shift to be seen in the characteristics of the patient population with LBP in The Netherlands. Compared to 1989-1992 the population in 2002-2003 is older, the patients are higher educated, less people have public insurance and less people are referred by the GP. This pattern is similar for all three subgroups, acute, sub-acute and chronic LBP.

\section{[ TABLE 3 ]}

\subsection{Number of treatment visits}

In 1989-1992 the average number of visits per treatment episode for LBP was 11.3 (S.D. 1.4). In 2002-2003, after adjusting for gender, age, insurance, education, referrer and physical therapist there is a significant decrease of 1.1 visits $(p<0.01)$ (Table 4$)$. Also, there were differences in changes in the number of treatment visits per subgroup: the number of treatments visits for patients with acute and sub-acute LBP significantly decreased between 1989 and $2002(p<0.01)$, while a significant increase in the number of treatments visits was observed for patients with chronic LBP. Analyses separately for patients with public health insurances and for patients with private health insurance showed that the number of treatment visits had decreased only in patients with public health insurance.

\section{[ TABLE 4 ]}

\subsection{Interventions}

Table 5 shows the top five of most used interventions on patients with LBP between 1989 and 1992 and between 2002 and 2003. In 1989-1992, massage therapy was the most frequently applied intervention (55.9\%), in 2002-2003 this intervention had the third position (38.5\%). The use of physical therapy modalities was frequently used in almost half of the treatments given between 1989 and 1992, while in 2002-2003 it was used in only 11.8\% of the treatments. The use of exercise therapy rose from $40.9 \%$ to $76.3 \%$. Changes in interventions for patients with acute, sub-acute and chronic LBP are largely similar.

\section{[ TABLE 5 ]}

\section{DISCUSSION AND CONCLUSION}

To our knowledge, this is the first study in the field of physical therapy focussing on changes in the management of patients with LBP over time using registration data. The results of our study suggest that since the 1990s there has been a rise in the proportion of patients with LBP visiting the physical therapist. Furthermore, the number of visits within a treatment episode in patients with LBP has slightly decreased; massage and physical modalities have become less popular, while exercise therapy has grown in popularity.

According to Statistics Netherlands, the number of patients visiting the physical therapist has increased over the last 10 years [13]. Therefore, one can conclude that the increase in the proportion of patients with LBP reflects an absolute increase in the number of patients with LBP visiting the physical therapist. This absolute increase corresponds with the finding that in 2001, compared to 1987, more Dutch people reported to suffer from LBP [14]. Our findings that patients with LBP visiting the 


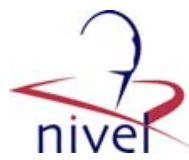

physical therapist have become older and higher educated can only partly be explained by a pattern that can be seen over the whole of the population in The Netherlands. Our results suggest that, apart from an absolute increase in patients, a shift can be observed in demographic characteristics of patients with LBP visiting the physical therapist.

Contrary to our expectations, the proportion of patients with acute LBP visiting the physical therapist practice in 2002 or 2003 did not decrease compared to 1989-1992. Our expectations were based on the Dutch guideline for general practitioners for the treatment of patients with LBP introduced in 1996, which advises against a referral to physical therapy in patients with acute complaints [7]. Previous research showed that Dutch GP's treat their patients in accordance to the standard in only $78 \%$ of the consultations [15]. Another possible reason for the referral of patients with acute LBP to the physical therapy practice is offered by van Tulder et al. [16] who state that prevention of chronicity should be one of the major aims in the management of LBP in primary care. Possibly, GP's refer some patients with acute LBP to the physical therapist to prevent chronicity. Research is necessary to determine the specific reasons why GP's refer patients with acute LBP to the physical therapist.

We observed a decrease of about $20 \%$ in the number of treatment visits over time in patients with acute low back pain. As this decrease was only observed in patients with public health insurance, it is expected that mainly reimbursement policy had influenced the number of treatment visits. The introduction of guidelines for physical therapy and general practice emphasizing an active approach on the basis of instruction and advice instead of supervised visits of exercise probably have less influenced the number of visits. As the average number of visits in practice differs substantially from the number of visits recommended in the guideline for physical therapy, a gap between practice and guideline might be the reason for this lack of influence.

Relatively large changes in the use of physical therapy modalities and exercise therapy are noticed in the current study, which indicate more evidence-based practising. And as the guideline was published just one year before the second registration, changes may increase. Although the changes in the use of interventions in patients with LBP support our hypotheses, there are some results that need highlighting. First, the rise in the use of instruction and advice in 2002 and 2003 compared to the period 1989-1992 is only one step up in the top five, while patient education is an important recommendation in the LBP guideline for physical therapist [5]. However, previous research showed that instructions and advice are given more frequently than therapists report in general [17]. Furthermore, in a study done in 1999 it was shown that physical therapists do comply with the recommendation about giving patient education. However, many differences in the amount of information provided were found [18]. Secondly, the use of passive mobilization has risen from $37.2 \%$ in 1989-1991 to 43.4\% in 2002-2003. This is contrary to the guideline which states that passive mobilization and traction is not useful in the treatment of patients with LBP [5]. Those findings, however, are in line with other studies reporting on the popularity of passive mobilizations among physical therapists for patients with low back pain $[19,20]$.

In 1991, the Dutch remuneration for treatments of patients with public health insurance changed from a remuneration system based on the number of separate interventions in one visit into a fixed payment per visit. This might be an alternative explanation for our findings. However, van Baar et al. [21] studied in detail the effects of this change and they neither found changes in the application of interventions, nor in the number of treatment visits. Therefore, it is not likely that our findings can be explained by this change.

There are a few limitations to this study that need to be mentioned. First of all, the two projects that this current study is based on were carried out in different ways; paper data in 1989-1991 and electronic data in 2002-2003. Furthermore, it was not possible to compare data on treatment goals and on the result of treatment. Those data could have been a valuable supplement to determine changes in the treatment of patients with LBP. Finally, in determining the change in the number of treatment visits only a limited number of variables were taken into account. It is very likely that psychosocial variables such as pain behaviour, coping style and locus of control have an influence in the number of treatment visits. In neither project data on psychosocial variables were collected.

On the basis of our study one can conclude that physical therapy management of LBP seems to have changed as a result of quality management by the profession and volume policy by government. 
Groenendijk, J.J., Swinkels, I.C.S., Bakker, D. de, Dekker, J., Ende, C.H.M. van den

Physical therapy mangement of low back pain has changed.

Health Policy: 2007, Vol. 80, nr. 3 p. 492-499, p.

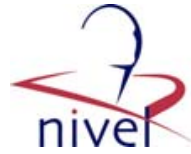

ACKNOWLEDGMENT

This study was funded by the Health Care Insurance Board (CvZ) of the Netherlands.

\section{TABLES}

Table 1

Overview of variables of both registration projects used for secondary analysis

\begin{tabular}{|c|c|c|c|}
\hline Variables & $1989-1992$ & $2002-2003$ & Used in analyses as \\
\hline \multicolumn{4}{|l|}{ Patient } \\
\hline Gender & Male; female & Male; female & Categorical \\
\hline Age & Date of birth & Date of birth & $\begin{array}{l}\text { Continuous: age in years at start treatment } \\
\text { episode }\end{array}$ \\
\hline Health insurance & $\begin{array}{l}\text { National health insurance }(\mathrm{Nhi}) \text {, } \\
\text { private health insurance (Phi) }\end{array}$ & $\begin{array}{l}\text { National health insurance }(\mathrm{Nhi}) \text {, } \\
\text { private health insurance (Phi) }\end{array}$ & Dichotomous \\
\hline Education & Ordinal, 8 categories & Ordinal, 8 categories & $\begin{array}{l}\text { Categorical ( } 4 \text { categories): Low (primary } \\
\text { ed.); Advanced (secondary ed., lower and } \\
\text { intermediate vocational ed., pre-university } \\
\text { ed.); High (higher vocational and } \\
\text { university ed.) Unknown (missing values) }\end{array}$ \\
\hline $\begin{array}{l}\text { Type of referring } \\
\text { physician }\end{array}$ & GP or medical specialist & GP or medical specialist & Dichotomous: GP; medical specialist \\
\hline Reason for referral & $\begin{array}{l}\text { As given by letter by the referrer; } \\
\text { coded with } \mathrm{ICPC}^{8} \text { by researchers }\end{array}$ & $\begin{array}{l}\text { As given by letter by the referrer; } \\
\text { coded with } \mathrm{ICPC}^{8} \text { by researchers }\end{array}$ & $\begin{array}{l}\text { Selection of patients with ICPC-code } \\
\text { L03.00 }\end{array}$ \\
\hline $\begin{array}{l}\text { Duration of complaint } \\
\text { at start episode }\end{array}$ & Date of start complaints & $\begin{array}{l}<2 \text { days; } 2-7 \text { days; } 1 \text { week to } 1 \\
\text { month; } 1-3 \text { months; } 3-6 \\
\text { months; } 6 \text { months to } 1 \text { year; } 1-2 \\
\text { years; }>2 \text { years; unknown }\end{array}$ & $\begin{array}{l}\text { Categorical: acute ( }<1 \text { month); sub-acute } \\
\text { (1-3 months); chronic ( }>3 \text { months) }\end{array}$ \\
\hline \multicolumn{4}{|l|}{ Treatment } \\
\hline Treatment sessions & Dates of treatment sessions & Dates of treatment sessions & Continuous; number of treatment sessions \\
\hline Interventions & $\begin{array}{l}\text { Based on Dutch classification; } \\
\text { registration at the level of the } \\
\text { treatment sessions: at most four } \\
\text { interventions could be registered } \\
\text { for each treatment session }\end{array}$ & $\begin{array}{l}\text { Based on Dutch classification; } \\
\text { registration at the level of the } \\
\text { treatment episode: at most three } \\
\text { interventions (out of } 25 \text { ) applied } \\
\text { in at least } 50 \% \text { of the sessions } \\
\text { could be registered }\end{array}$ & $\begin{array}{l}\text { Categorical; top } 5 \text { of most used } \\
\text { interventions per episode }\end{array}$ \\
\hline
\end{tabular}

Table 2

Proportion of patients, in 1989-1992 and 2002-2003, with LBP related to the total population of patients in the Netherlands visiting the physical therapist

\begin{tabular}{lll}
\hline & \multicolumn{2}{l}{ Total population } \\
\cline { 2 - 3 } & $\begin{array}{l}1989-1992 \\
(n=16.340)\end{array}$ & $\begin{array}{l}2002-2003 \\
(n=7.561)\end{array}$ \\
\hline Patients with LBP \% & 11.9 & $15.4^{* *}$ \\
Gender \% & & \\
Men with LBP & 6.5 & 7.0 \\
Women with LBP & 5.4 & $8.4^{* *}$ \\
& & \\
Age \% & & \\
18-35 years & 4.4 & $3.8^{*}$ \\
35-55 years & 5.2 & $6.7^{* *}$ \\
$>55$ years & 2.4 & $4.9^{* *}$ \\
Duration of LBP \% & & \\
Acute & 7.0 & 7.1 \\
Sub-acute & 2.6 & $3.2^{*}$ \\
Chronic & 2.3 & $5.1^{* *}$ \\
\hline
\end{tabular}

${ }^{*} p<0.05,{ }^{* *} p<0.01$. 
Groenendijk, J.J., Swinkels, I.C.S., Bakker, D. de, Dekker, J., Ende, C.H.M. van den Physical therapy mangement of low back pain has changed.

Health Policy: 2007, Vol. 80, nr. 3 p. 492-499, p.

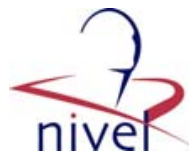

Table 3

Characteristics of patients with LBP in the Netherlands visiting the physical therapist between 1989 and 1992 and between 2002 and 2003

\begin{tabular}{|c|c|c|c|c|c|c|c|c|}
\hline & \multicolumn{2}{|l|}{ Total } & \multicolumn{2}{|l|}{ Acute LBP } & \multicolumn{2}{|c|}{ Sub-acute LBP } & \multicolumn{2}{|c|}{ Chronic LBP } \\
\hline & $\begin{array}{l}1989-1992 \\
(n=1948)\end{array}$ & $\begin{array}{l}2002-2003 \\
(n=1200)\end{array}$ & $\begin{array}{l}1989-1992 \\
(n=1125)\end{array}$ & $\begin{array}{l}2002-2003 \\
(n=551)\end{array}$ & $\begin{array}{l}1989-1992 \\
(n=425)\end{array}$ & $\begin{array}{l}2002-2003 \\
(n=254)\end{array}$ & $\begin{array}{l}1989-1992 \\
(n=377)\end{array}$ & $\begin{array}{l}2002-2003 \\
(n=387\end{array}$ \\
\hline Average age (years) & 42.6 & $48.3^{* *}$ & 42.8 & $48.7^{* *}$ & 42.4 & $47.1^{* *}$ & 41.9 & $48.4^{* *}$ \\
\hline Standard deviation & 14.8 & 16.2 & 14.6 & 15.8 & 15.0 & 16.2 & 15.3 & 16.8 \\
\hline Education \% & & $* *$ & & $* *$ & & $* *$ & & $* *$ \\
\hline Low & 15.4 & 10.5 & 15.0 & 8.7 & 17.4 & 10.4 & 14.5 & 13.1 \\
\hline Advanced & 77.5 & 72.3 & 76.7 & 69.3 & 77.4 & 76.0 & 79.6 & 73.8 \\
\hline High & 7.1 & 17.2 & 8.3 & 21.9 & 5.2 & 13.5 & 5.9 & 13.1 \\
\hline \multicolumn{9}{|l|}{ Public } \\
\hline Insurance \% & 79.2 & $69.7^{* *}$ & 77.7 & $65.2^{* *}$ & 83.1 & $70.1^{* *}$ & 80.1 & $76.0^{* *}$ \\
\hline Referral & & & & & & & & \\
\hline by GP \% & 97.4 & $94.7^{* *}$ & 98.2 & $96.2^{* *}$ & 96.9 & 96.9 & 95.2 & $91.0^{* *}$ \\
\hline
\end{tabular}

${ }^{*} p<0.05,{ }^{* *} p<0.01$.

Table 4

Differences between 1989-1992 and 2002-2003 in the number of visits of a treatment episode for patients with LBP, corrected for gender, age, level of education, health insurance, type of referring physician, duration of complaints taking the variation among therapists and practices into account

\begin{tabular}{|c|c|c|c|c|c|c|c|c|}
\hline & \multicolumn{2}{|l|}{ Total } & \multicolumn{2}{|l|}{ Acute LBP } & \multicolumn{2}{|c|}{ Sub-acute LBP } & \multicolumn{2}{|c|}{ Chronic LBP } \\
\hline & $\begin{array}{l}1989-1992 \\
(n=1948)\end{array}$ & $\begin{array}{l}2002-2003 \\
(n=1200)\end{array}$ & $\begin{array}{l}1989-1992 \\
(n=1146)\end{array}$ & $\begin{array}{l}2002-2003 \\
(n=559)\end{array}$ & $\begin{array}{l}1989-1992 \\
(n=425)\end{array}$ & $\begin{array}{l}2002-2003 \\
(n=254)\end{array}$ & $\begin{array}{l}1989-1992 \\
(n=377)\end{array}$ & $\begin{array}{l}2002-2003 \\
(n=387)\end{array}$ \\
\hline $\begin{array}{l}\text { Average number of } \\
\text { sessions }\end{array}$ & 11.3 & 10.3 & 11.4 & 9.2 & 10.8 & 9.6 & 11.8 & 12.3 \\
\hline Median & 11.2 & 10.2 & 11.3 & 9.1 & 10.7 & 9.6 & 11.6 & 12.0 \\
\hline Standard deviation & 1.4 & 2.1 & 1.5 & 1.8 & 0.9 & 1.3 & 1.3 & 1.7 \\
\hline Min-Max & $7.4-17.7$ & $5.8-18.1$ & $7.4-17.7$ & $5.8-16.5$ & $7.8-14.5$ & $6.2-13.9$ & $8.2-17.2$ & $8.1-18.1$ \\
\hline Adjusted difference & \multicolumn{2}{|c|}{$-1.06^{*}$} & \multicolumn{2}{|c|}{$-2.15^{*}$} & \multicolumn{2}{|c|}{$-1.25^{*}$} & \multicolumn{2}{|c|}{$0.44^{*}$} \\
\hline CI & \multicolumn{2}{|c|}{$(-1.20 ;-0.93)$} & \multicolumn{2}{|c|}{$(-2.32 ;-1.98)$} & \multicolumn{2}{|c|}{$(-1.42 ;-1.07)$} & \multicolumn{2}{|c|}{$(0.23 ; 0.65)$} \\
\hline
\end{tabular}

Table 5

Top five of the most frequently applied interventions by physical therapists on patients with LBP in 1989-1992 and 2002-2003 in The Netherlands

\begin{tabular}{|c|c|c|c|c|c|}
\hline & \multicolumn{2}{|l|}{ 1989-1992 } & \multicolumn{2}{|l|}{$2002-2003$} & \multirow[t]{2}{*}{$p$} \\
\hline & Percentage & Order & Percentage & Order & \\
\hline Massage & 55.9 & 1 & 38.5 & 3 & $<0.001$ \\
\hline Physical therapy modalities & 45.1 & 2 & 11.8 & 5 & $<0.001$ \\
\hline Exercise therapy & 40.9 & 3 & 76.3 & 1 & $<0.001$ \\
\hline Passive mobilization & 37.1 & 4 & 43.4 & 2 & 0.001 \\
\hline Instruction and advice & 22.7 & 5 & 29.1 & 4 & $<0.001$ \\
\hline
\end{tabular}

\section{REFERENCES}

1. Wimmers R, Swinkels I, Konink de M, Bakker de D, Ende van den E. Jaarboek Li PZ 2002. Deel 1: Beroepsgroep fysiotherapie [Yearly of the LiPZ-registration network, part: physical therapy]. Utrecht: NIVEL; 2003.

2. Sluijs EM,Wagner C. Progress in the implementation of Quality Management in Dutch health care: 1995-2000. International Journal for Quality in Health Care 2003;15(3):223-34.

3. Sluijs EM, Outinen M, Wagner C, Liukko M, de Bakker D. The impact of legislative versus non-legislative quality policy in health care: a comparison between countries. Health Policy 2001;58(2):99-119.

4. van derWees PJ, Hendriks EJM, Veldhuizen RJ. Quality assurance in the Netherlands: from development to implementation and evaluation. Dutch Journal of Physical Therapy Special Issue International WCPT 2003.

5. Bekkering GE, Hendriks HJM, Koes BW, Oostendorp RAB, Ostelo RWJG, Thomassen JMC, et al. Dutch physiotherapy guidelines for low back pain. Physiotherapy 2003;89(2):82-96. 
6. Health Council of the Netherlands. Effectiveness of physical therapy; electrotherapy, lasertherapy, ultrasound therapy. 1999/20. The Hague: Health Council of the Netherlands; 1999.

7. Koes BW, Tulder van MW, Ostelo R, Burton AK, Waddell G. Clinical guidelines for the management of low back pain in primary care. An international comparison. Spine 2001;26(22):2504-14.

8. Pijnenborg A, Berkel van DM, Ende van den E, Ravensberg van CD, Dekker J. De beperkende maatregel fysiotherapie, oefentherapie-Cesar en oefentherapie-Mensendieck: resultaten van het evaluatie-onderzoek [The impact of the regulation limiting the reimbursement of physical therapy and exercise therapy]. Utrecht: NIVEL; 1998.

9. Valk van der R, Dekker J, Baar van ME. Physical therapy for patients with back pain. Physiotherapy 1995;81(6):345-51.

10. Lamberts $\mathrm{H}$, Wood M, Hofman-Okkes I. International classification of primary care in the European Community: with a multi-language layer. Oxford: Oxford University Press; 1993.

11. Hendriks HJM. Physiotherapist's consultation in general practice. thesis. Maastricht: Universiteit Maastricht; 2000.

12. Tulder van MW, Koes BW, Bouter LM. A cost-of-illness study of back pain in The Netherlands. Pain 1995;62:233-40.

13. Statistics Netherlands. http://www.cbs.nl/. Accessed August 15, 2004.

14. Westert GP, Schellevis FG, de Bakker DH, Groenewegen PP, Bensing JM, van der Zee J. Monitoring health inequalities through general practice: the second Dutch national survey of general practice. European Journal of Public Health 2005;15(1):59-65.

15. Schers H, Braspenning J, Drijver R, Wensing M, Grol R. Low back pain in general practice: reported management and reasons for not adhering to the guidelines in the Netherlands. British Journal of General Practice 2000;50:640-4.

16. Tulder van MW, Koes BW, Metsemakers JFM, Bouter LM. Chronic low back pain in primary care: a prospective study on the management and course. Family Practice 1998;15(2):12632.

17. Sluijs EM. Patient education in physical therapy. thesis. Utrecht: NIVEL; 1991.

18. Kerssens JJ, Sluijs EM, Verhaak PFM, Knibbe HJJ, Hermans IMJ. Back care instructions in physical therapy: a trend analysis of individualized back care programs. Physical Therapy 1999;79(3):286-95.

19. Foster NF, Thompson KA, Baxter GD, Allen JM.Management of nonspecific low back pain by physiotherapists in Britain and Ireland. A descriptive questionnaire of current clinical practice. Spine 1999;24:1332-42.

20. Gracey JH, McDonough SM, Baxter GD. Physiotherapy management of low back pain. A survey of current practice in Northern Ireland. Spine 2002;27(4):406-11.

21. van Baar ME, Abrahamse H, Dekker J. Geen effect van invoering van een nieuw honoreringsstelsel op het handelen van fysiotherapeuten [No effect of a change in remuneration system on the professional behaviour of physical therapists]. Tijdschr Soc Gezondheidsz 1995;73(3):141-8. 